\title{
DIMENSIONAL ANALYSIS OF THE TRACTOR TRACTIVE EFFICIENCY PARAMETERS
}

\author{
Abdol Majid MOINFAR, Gholamhossein SHAHGHOLI* \\ University of Mohaghegh Ardabili, Faculty of Agriculture and Natural Resources, \\ Department of Biosystem Engineering, Iran
}

\begin{abstract}
One of the important parameters of the tractor's performance - tractive efficiency - should be improved during agricultural operation; this paper observes this parameter using the Arvid 354 tractor with a chisel plough. Parameters taken into account included the tillage parameters, such as tillage depth, travel velocity, rake angle, tine width and tractor weight, as well as soil engineering properties, including cohesion and soil bulk density. Experimental results indicated that the tractor tractive efficiency increased with increasing of the tillage depth and rake angle, whereas travel velocity did not show any specific impact on it. Theoretical equations were extracted for drawbar pull, tyre slip and gross traction using dimensional analysis and experimental data. Finally, by combining these equations, the tractive efficiency was estimated. Obtained model was evaluated by means of obtained experimental data. Results showed that the proposed model is capable of predicting tractive efficiency as a function of soil parameters, tractor weight and tillage parameters of the chisel plough.
\end{abstract}

Keywords: tractive efficiency; tyre slip; chisel; dimensional analysis

Nowadays, it is necessary that tractors utilized in agriculture, especially of moderate and high energy rate, are able to adequately deal with drawbar duties. Tractor energy rate is determined by the quantity of the work accomplished relative to the cost spent necessary for work to be carried out. Drawbar duty is defined by the required draft and forward velocity of the tractor. Therefore, desired tractor converts all the fuel energy into the effective power at the tractor drawbar (Zoz and Grisso, 2003). Realization and prediction of the tractor efficiency has been a main objective for many researchers. Tractor efficiency is affected by draft elements, soil conditions, implement type and the tractor's configuration with the implement (Brixius, 1987). It is necessary to realize the traction for predicting the tractor efficiency in field. Together with obtained base information from field trials with the tractor, traction equations provide a foundation for prediction of tractor efficiency (Zoz and Grisso, 2003). Tractive efficiency is determined by the specifications of tractor traction, torque, rolling resistance and wheel slip (Grisso et al., 2006) Tractive efficiency is calculated by means of Eq. (1):

$$
T E=\frac{\text { Drawbar Pull }}{\text { Gross Traction }}(1-\text { Slip })
$$

The power requirement of any used implement is influenced by the condition of soil, such as its texture, moisture content and its compactness, and the designed dimension of the tillage tool (Oskin and Tarasenko, 2017). Specific draft (required draft force per cross section of loosed area of the soil) and energy requirement of mouldboard plough, chisel plough and disc harrow at different soil conditions were studied by Arvidson et al. (2004). Chisel plough showed the highest value of specific draft, while mouldboard plough and disc harrow showed relatively lower values of specific draft, respectively. This difference can be due to the different geometry of implements and soil break-up mode. Relation between increasing the weight of disc plough and varying the tilling depth and required draft was investigated by Olatunji et al. (2009). The model extracted from the field trials showed that draft requirement of disc plough increased with increasing travel velocity and soil moisture content. Increment in disc plough weight showed significant effect on the working depth of the implement. Mamman and Oni (2005) modelled the draft requirement of a chisel plough by performing tests in the soil bin. Following parameters were investigated in this study: rake angle, slide angle, depth and travel velocity. Increment of tilling depth provided an increase in required draft. Furthermore, increasing the levels of rake and slide angles and the cutting edge height had significant impact on draft, resulting in its increase. In general, dimensional analysis is powerful and applicable analytical method, designed to find or check correlations among physical quantities by using their dimensions. It generalizes the experimental results. General analysis of the phenomena without limiting to a single element of the performed experiments reduces necessary experimental work, as well as spent time and expenses. Obtained results can be presented to experts in simplified version, allowing easier application (Murphy, 1950). 
The objectives of the study were to perform an experimental investigation in terms of effect of tillage depth, rake angle and travel velocity on the soil/chisel tine interaction force. New theoretical model was developed for predicting tine force, tyre slip and gross traction by means of dimensional analysis method. Finally, constants of the model were calculated on the basis of the conducted test data.

\section{Material and methods}

Considering this research, the parameters affecting the forces acting on

the blade and the tractor tyre slip are presented in Table 1 , including soil mechanical and physical properties, tool dimensions, operating conditions and the dynamic load on the tractor drive wheel.

Table 1 The effective factors of soil and tool interaction

\begin{tabular}{|l||c|c|}
\hline Definition & Effective factors & Symbol \\
\hline \hline $\begin{array}{l}\text { Soil bulk density } \\
\left(\mathbf{g} \cdot \mathbf{c m}^{-\mathbf{3}} \mathbf{)}\right.\end{array}$ & soil engineering properties & $\gamma$ \\
\cline { 2 - 3 } & cohesion $(\mathrm{kPa})$ & $\mathrm{C}$ \\
\hline \multirow{2}{*}{ Tool width $(\mathbf{m})$} & tool design parameters & $\mathrm{W}$ \\
\cline { 2 - 3 } & rake angle $(\mathrm{deg})$ & $\alpha$ \\
\hline \multirow{2}{*}{ Velocity $\left(\mathbf{m} \cdot \mathbf{s}^{-\mathbf{1}}\right)$} & tool depth $(\mathrm{m})$ & $\mathrm{d}$ \\
\hline \multirow{2}{*}{ Tractor characteristics } & $\begin{array}{r}\text { operational conditions } \\
\text { dynamic rear wheel } \\
\text { loads }(\mathrm{N})\end{array}$ & $\mathrm{U}$ \\
\hline
\end{tabular}

Regarding the parameters presented in Table 1, the ones involved in the applied force on the tillage tool $(P)$ and the tractor tyre slip $(S)$ can be functions of variables as follows:

$$
\begin{gathered}
P=f(v, d, w, \alpha, \gamma, c) \\
S=f(v, d, w, \alpha, \gamma, c, W)
\end{gathered}
$$

According to Buckingham's theorem, the number of invariants and repetitive invariants were $(7,8)$ and $(3)$, respectively Eqs. $(2,3)$. Then $(4,5)$ constant $\Pi_{i}$-values are computed from Eqs. $(4,5)$. In terms of this study, three repetitive invariants were travel velocity $(v)$, specific weight $(\gamma)$ and tool width $(w)$.

By means of the conventional Buckingham's theorem, dimensionless parameters can be formed in a matrix form and, with its solution, the following dimensionless parameters were calculated:

$$
\left\{\begin{array}{c}
\Pi_{1}=\frac{P}{v^{2} \gamma w^{2}} \\
\Pi_{2}=\frac{c}{v^{2} \gamma} \\
\Pi_{3}=\frac{d}{w} \\
\Pi_{4}=\sin \alpha
\end{array}\right.
$$

$$
\left\{\begin{array}{c}
\Pi_{1}=S \\
\Pi_{2}=\frac{c}{v^{2} \gamma} \\
\Pi_{3}=\frac{d}{w} \\
\Pi_{4}=\frac{W}{v^{2} \gamma w^{2}} \\
\Pi_{5}=\sin \alpha
\end{array}\right.
$$

Eqs. $(6,7)$ were taken as the final forms of the equations for estimating the draft and the tyre slip:

$$
\begin{gathered}
P=\left(v^{2} \gamma w\right)\left(\frac{C+C_{a}}{v^{2} \gamma}\right)^{n_{1}}\left(\frac{d}{w}\right)^{n_{2}}(\sin \alpha)^{n_{3}} \\
S=\left(\frac{C}{v^{2} \gamma}\right)^{n_{1}}\left(\frac{d}{w}\right)^{n_{2}}\left(\frac{W}{v^{2} \gamma w^{2}}\right)^{n_{3}}(\sin \alpha)^{n_{4}}
\end{gathered}
$$

Tractor gross traction $(R)$ and affecting factors were presented as Eq. (8):

$$
R=n_{1} W\left(\frac{v^{2} \gamma}{c}\right)^{n_{2}}
$$

In Eq. (6), (7) and (8) constant values of $n_{1}, n_{2}, n_{3}$, and $n_{4}$ were calculated using statistical computation of the measured experimental data.

Field experiments were conducted at the Research Farm of Ardabil Agricultural Research Center (48 $55^{\circ} 47^{\prime \prime} \mathrm{E}$ longitude; 37 33'57" N latitude; and $1350 \mathrm{~m}$ above sea level) in the northwest of Iran. The site had 0 to $1 \%$ slope and had been utilized for many years using conventional tillage; there were stubble residues of barley from the previous farming season. Several characteristics of the experimental field soil are presented in Table 2.

Table 2 Properties of the tested soi

\begin{tabular}{|l||c|}
\hline Soil texture & Silt-sand \\
\hline \hline Percentage of clay $(<\mathbf{0 . 0 0 2} \mathbf{~ m m})$ & $47 \%$ \\
\hline Percentage of silt $\mathbf{( 0 . 0 0 2} \mathbf{+ 0 . 0 5} \mathbf{~ m m})$ & $43 \%$ \\
\hline Percentage of sand $(>\mathbf{0 . 0 5} \mathbf{~ m m})$ & $10 \%$ \\
\hline Cohesion (c) & $2.3 \mathrm{kPa}$ \\
\hline Angle of internal friction & $35^{\circ}$ \\
\hline Moisture content & $250 \mathrm{~g} \cdot \mathrm{kg}^{-1}$ \\
\hline Dry density for the experiment & $1.19 \mathrm{~g} \cdot \mathrm{cm}^{-3}$ \\
\hline Humidity for the experiment & $250 \mathrm{~g} \cdot \mathrm{kg}^{-1}$ \\
\hline
\end{tabular}

Specification of the tractor used in this study (Arvid 354) is presented in Table 3. Two tine chisel ploughs with the tine width of $3 \mathrm{~cm}$ and the maximum tilling depth of $25 \mathrm{~cm}$ (distance between two tines was $1 \mathrm{~m}$ ) were used. The chassis underwent several adjustments in order to create different rake angles for the tine tip. 
Table 3 Specification of the tractor used in this study (Arvid 354)

\begin{tabular}{|l||c|c|}
\hline Specifications & Unit & Value \\
\hline Type of tractor engine & - & Diesel (3 cylinders) \\
\hline Capacity of the cylinders & $\mathrm{I}$ & 2.230 \\
\hline $\begin{array}{l}\text { Diameterxstroke of the } \\
\text { cylinder }\end{array}$ & $\mathrm{mm}$ & $95 \times 105$ \\
\hline Engine power & $\mathrm{kw}$ & $25.8(2000 \mathrm{rpm})$ \\
\hline Tractor weight & $\mathrm{kg}$ & 1385 \\
\hline Tractor type & - & 2 wheel drive (rear wheels) \\
\hline
\end{tabular}

Three independent variables were forward travel velocity, tilling depth and tine rake angle. There were investigated 36 treatments with 3 tillage depths of $10,15,20 \mathrm{~cm}, 3$ rake angles of $60,75,90$ degrees and 4 forward velocities of 0.5 , $1,1.35,1.7 \mathrm{~m} \cdot \mathrm{s}^{-1}$ in three replications on tractive force and tyre slip. To measure the gross traction of chisel plough, two tractors were connected according to RNAM method with drawbar dynamometer (Rnam, 1983).

Wheel velocity was measured by an inductive proximity sensor mounted in line with the outer edge of a 34-tooth sprocket fixed inside the rear wheel (Fig. 1). It detected passing of each tooth during the wheel rotation. With each full rotation of the gear or the rear wheel, digital display of pulses meter, which was attached to magnetic sensor, showed the number of gear teeth. In order to calculate the wheel rotation, shown number was divided by 34 . The travelled distance was calculated by measuring the perimeter of the rear wheel. Tyre perimeter was calculated by dividing the travelled distance by the rear wheel rotation number when the tractor was under traction work. Subsequently, dynamic rolling radius was determined by dividing the tyre perimeter by $2 \pi$. The tractor actual velocity was easily calculated by measuring the time required to travel this distance using a stopwatch. The following equation was used to calculate the slip:

$$
S(\%)=1-\frac{v_{a}}{v_{t}} \times 100
$$

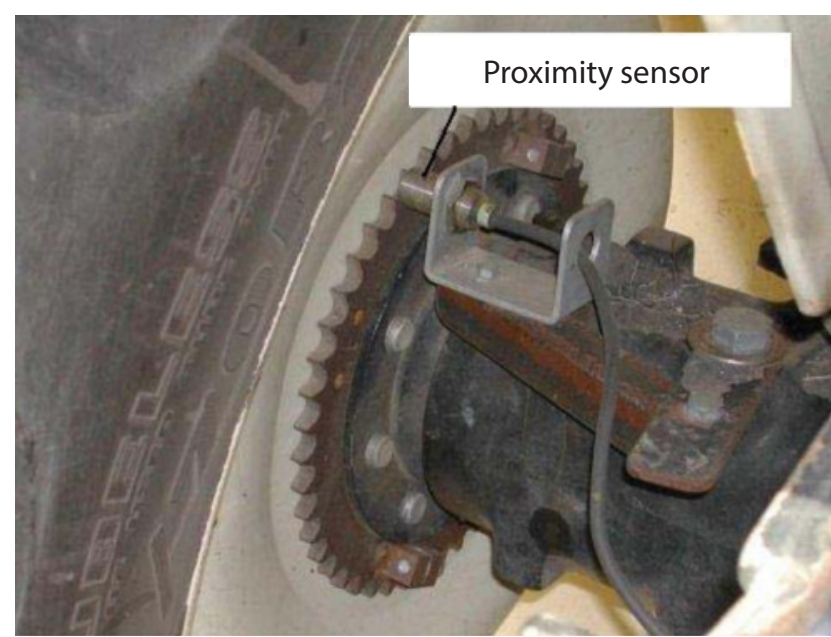

Fig. 1 Wheel velocity transducer for measurement of tyre rotation where:

$v_{a} \quad-$ actual velocity, $\mathrm{m} \cdot \mathrm{s}^{-1}$

$v_{t} \quad-$ theoretical velocity, $\mathrm{m} \cdot \mathrm{s}^{-1}$

Required draft was measured using a dynamometer developed by Abbaspour-Gilandeh and Khanramaki (2013) (Fig. 2). The maximum dynamometer capacity for draft measurement was $35 \mathrm{kN}$. It included a stable frame and two extended octagonal rings for measurement of draft forces in three directions of a coordinate system. The tillage tool was installed on the dynamometer and the dynamometer was mounted to the tractor three-point hitch. It was calibrated at the field according to the method presented by AbbaspourGilandeh and Khanramaki (2013). The data acquisition system, commercial strain gauges installed on two extended octagonal rings (EOR), data logger (Data Taker Co, Australia) and laptop were utilized for measurement.

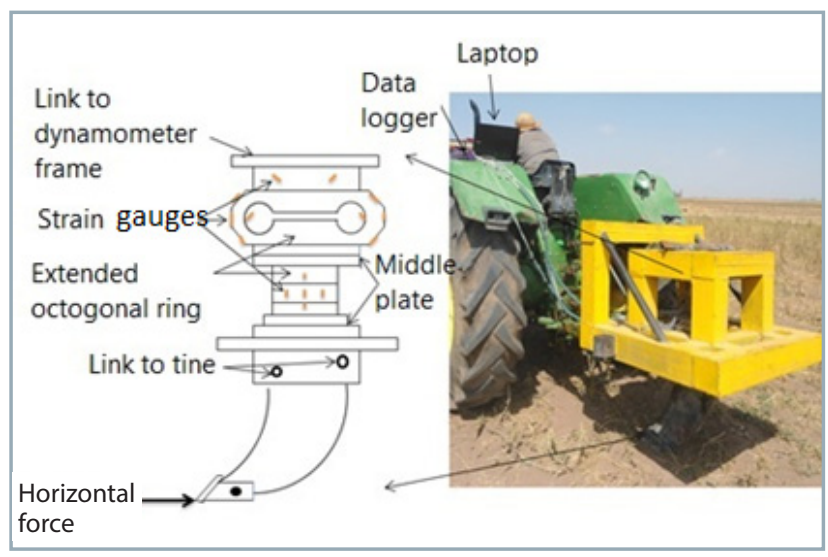

Fig. 2 Dynamometer and data logging parts used in field test

Dynamic load-wheel drive was calculated by summation of the static load and weight transfer and the following equation was used to estimate the dynamic load on tyre (Barger et al., 1963):

$$
W_{d}=W_{s}+P\left(\frac{H}{X}\right)
$$

where:

$W_{s}$ - static rear wheel load, $\mathrm{N}$

$H \quad$ - drawbar height, $\mathrm{m}$

$X \quad$ - wheelbase, $\mathrm{m}$

Tilling depth was measured using an ultrasonic sensor installed under the dynamometer frame. In such a manner, the distance between the frame and ground surface was measured precisely and continuously. Finally, tractive efficiency was calculated by means of Eq. (1).

\section{Results and discussion}

Obtained data were analyzed on the basis of factorial experiment using ANOVA. Treatment means were compared by Duncan's multiple range test SPSS21 software. Table 4 shows the comparison of the tractive efficiency means at different tilling depths, travel velocities and rake angles. 
Table 4 Comparison of tractive efficiency means at different levels of tilling depths, rake angles and travel velocities

\begin{tabular}{|c|c|c|c|c|c|c|c|c|c|c|}
\hline \multicolumn{11}{|c|}{ Rake angle (degree) } \\
\hline \multirow{3}{*}{$\begin{array}{l}\text { Velocity } \\
\left(\mathrm{m} \cdot \mathrm{s}^{-1}\right)\end{array}$} & \multicolumn{3}{|c|}{60} & \multicolumn{3}{|c|}{75} & \multicolumn{3}{|c|}{90} & \multirow[b]{3}{*}{ Average } \\
\hline & \multicolumn{3}{|c|}{ tilling depth $(\mathrm{cm})$} & \multicolumn{3}{|c|}{ tilling depth $(\mathrm{cm})$} & \multicolumn{3}{|c|}{ tilling depth $(\mathrm{cm})$} & \\
\hline & 10 & 15 & 20 & 10 & 15 & 20 & 10 & 15 & 20 & \\
\hline 0.75 & $38.2 \beta$ & $45.22^{\mathrm{s}}$ & $48.67^{j}$ & $39.6^{z}$ & $47.5^{p}$ & $48.7^{e}$ & $43.5^{v}$ & $49.9^{1}$ & $50.6^{d}$ & $45.8^{\mathrm{A}}$ \\
\hline 1 & $36.36 \beta$ & $45.26^{5}$ & 49.6 & $39.1^{y}$ & $48.1^{\circ}$ & $50.7^{\mathrm{fg}}$ & $43.8^{t}$ & $51.7^{\mathrm{h}}$ & $54.2^{c}$ & $46.6^{B}$ \\
\hline 1.35 & $33.54 \varphi$ & $43.27^{\mathrm{u}}$ & $48.5^{n}$ & $37.1 \alpha$ & $46.4^{9}$ & $50.8^{i}$ & $42.1^{w}$ & $52^{9}$ & $55^{\mathrm{b}}$ & $45.5^{C}$ \\
\hline 1.7 & $31.6 \delta$ & $42.48^{v}$ & $49^{m}$ & $35.6 Y$ & $45.4^{r}$ & $51.9^{\text {ef }}$ & $40.3^{x}$ & $50.3^{k}$ & $55.1^{\mathrm{a}}$ & $44.6^{\mathrm{D}}$ \\
\hline Average & $34.9^{\mathrm{E}}$ & $44^{\mathrm{F}}$ & $49^{G}$ & $37.9^{H}$ & $46.9^{1}$ & $50.6^{j}$ & $42.4^{\mathrm{K}}$ & $51^{\mathrm{L}}$ & $53.7^{\mathrm{M}}$ & - \\
\hline
\end{tabular}

The means with different letters show significant difference at $5 \%$. Different letters of upper indices show significant difference between treatments.

According to Table 4, tractor net traction increased significantly with an increase in travel velocity. The highest net traction - $1.146 \mathrm{kN}$ - was observed at the velocity and slip of $1.7 \mathrm{~m} \cdot \mathrm{s}^{-1}$ and $12.7 \mathrm{~m} \cdot \mathrm{s}^{-1}$, respectively; while the lowest net traction $-0.859 \mathrm{kN}$ - was observed at the velocity and slip of $0.5 \mathrm{~m} \cdot \mathrm{s}^{-1}$ and $25 \%$, respectively. Increased traction with the travel velocity increment has been reported by Grisso et al. (1994). This phenomenon is largely due to higher soil acceleration because of fast movement of the tool. Soil acceleration increased the tensile strength at least because of two reasons. Firstly, in this manner, vertical force on the involved surface of the tool with soil was increased and thereby there was an increase in frictional resistance; and secondly, there is an increase in kinetic energy applied to the soil (Kepner et al., 1978).

Increasing of the tillage depth showed a significant increase in the tractor net traction. The highest net traction $1.444 \mathrm{kN}$ - was related to the depth and slip of $20 \mathrm{~cm}$ and $23.3 \%$, respectively, while the lowest value $-0.555 \mathrm{kN}-$ was obtained at the depth and slip of $10 \mathrm{~cm}$ and $12.8 \%$, respectively. Increment of soil tensile strength with increase in depth has been reported by Al-Janobi and Al-Suhaibani (1998). Normally, soil compaction naturally increases with depth increment, affecting its mechanical strength and, consequently, influencing the traction force. In addition, soil weight on the blade is increased by increasing of the tilling depth, which can lead to increment of friction between the blade and soil, thus significantly affecting the traction force (Al-Janobi and Al-Suhaibani, 1998).

Increasing rake angle of tillage tool increased the net traction of the tractor significantly. The maximum net traction of $1.23 \mathrm{kN}$ was at the rake angle and slip of $90^{\circ}$ and $19.57 \%$, respectively, and the minimum value of $1.006 \mathrm{kN}$ was obtained at the rake angle and slip of $60^{\circ}$ and $16.64 \%$, respectively. Increasing of the rake angle from $60^{\circ}$ to $90^{\circ}$ caused higher vertical stress on soil, and soil movement on the blade hardly takes place. Consequently, higher shear strain occurs in the soil, leading to an increase in shear force and rupture of soil layers over each other, which consequently increases the disturbed area; therefore, the required traction force increased (Grisso et al., 2007). Söehne (1956) stated that approximately $60 \%$ of the resistance against the movement of the tilling blade is due to the friction between the blade and soil and the soil internal friction. Therefore, contact surface between the soil and the blade increased in a rake angle of $90^{\circ}$ and traction force is increased due to the friction force.

Results show that the slip significantly increases with decreasing travel velocity. The highest percentage of the slip at velocity of $0.5 \mathrm{~m} \cdot \mathrm{s}^{-1}$ was $24.44 \%$ and the minimum percentage of the slip was $12.1 \%$ at velocity of $1.7 \mathrm{~m} \cdot \mathrm{s}^{-1}$. This process can be explained by reduction of the interaction time of wheel and soil by increasing velocity. Furthermore, in such a manner, the wheel leaves the area before loosening soil preventing the tractor's wheel from normal movement. In this study, the slip decreased by increasing the weight on the drive wheel, hence, at higher velocity, lower weight is required, implying that the slip decreases by increasing the velocity (Kumar and Aggarwal, 2001). Results show that with increasing depth, there was a significant increase in the percentage of tractor drive wheel slip. Therefore, it can be said that wheel tractive force with soil is increased by increasing the tilling depth, leading to increment in the drive wheel slip. Moreover, by increasing tilling depth and tractive force, soil shear deformation increases, resulting in increment in the slip value (Zoz and Grisso, 2003). Slip can be reduced with increasing velocity, as has been reported by other researchers. Shebi et al. (1988) evaluated three tractor parameters - velocity, power and tyre inflation pressure with different cultivation implements on the tractor slip and drawbar pull. By increasing the velocity of the tractor from 4 to $11 \mathrm{~km} \cdot \mathrm{h}^{-1}$, wheel slip decreased from 15 to $8.5 \%$. Increase in rake angle results in increase in depth and slip. Since wheel traction increases by increasing the rake angle, traction force increment leads to increment in soil shear deformation and slip percentage.

In order to obtain the coefficient $n_{1}$, the experimental data of required draft, slip, gross traction (as dependent parameters) and travel velocity (as independent variable) were plotted in the Excel software. For calculation of the $n_{2}$, $n_{3}$ and $n_{4}$ factors, the same method was used, except that the independent variables for $n_{2}$ and $n_{3}$ in each graph were tilling depth and rake angle, respectively. Finally, equations for estimating the required draft, tyre slip and gross traction were as follows:

$$
P=0.0082\left[\left(v^{2} \gamma w\right)\left(\frac{C}{v^{2} \gamma}\right)^{0.84}\left(\frac{d}{w}\right)^{1.46}(\sin \alpha)^{2.6}\right]
$$




$$
\begin{gathered}
S=2.3\left[\left(\frac{C}{v^{2} \gamma}\right)^{0.41}\left(\frac{d}{w}\right)^{0.95}\left(\frac{W}{v^{2} \gamma w^{2}}\right)^{-0.054}(\sin \alpha)^{1}\right] \\
R=0.000338\left[W\left(\frac{v^{2} \gamma}{c}\right)^{0.45}\right]
\end{gathered}
$$

Ultimately, it is possible to combine Eqs. $(11,12$ and 13) and contract them into Eq. (1) to predict the traction efficiency. Results of Eqs. (11, 12 and 13), together with the experimental data for the vertical blade (at rake angle of $90^{\circ}$ ), are shown in Fig. 3a. Predicted data obtained by means of Eqs. (11, 12 and 13) showed a good correlation with the experimental data. Average error of the developed model at the depths of 10,15 and $20 \mathrm{~cm}$ were $0.7 \%, 0.9 \%$ and $0.87 \%$, respectively. The same qualitative results were observed at rake angles $60^{\circ}$ and $75^{\circ}$. Figs $3 \mathrm{~b}$ and $3 \mathrm{c}$ illustrate the results.

Fig. 4 shows that there is no clear correlation between the tractive efficiency variation as function of the traction and slip change. It can be due to the concurrent dependence of tractive efficiency on the traction and slip. The peak tractive efficiency of $55 \%$ was obtained at slip range of $15-20 \%$ and the maximum value of tractive force. In general, tractive efficiency increased with increment in slip and subsequently after reaching a peak value at slip range of $15-20 \%$, then, it declined again.

Osinenko et al. (2015) have reported this trend; they observed the maximum tractive efficiency for different soil types at slip of $13.9,18.6$ and $20.53 \%$, respectively. Differences in the maximum tractive efficiency resulted
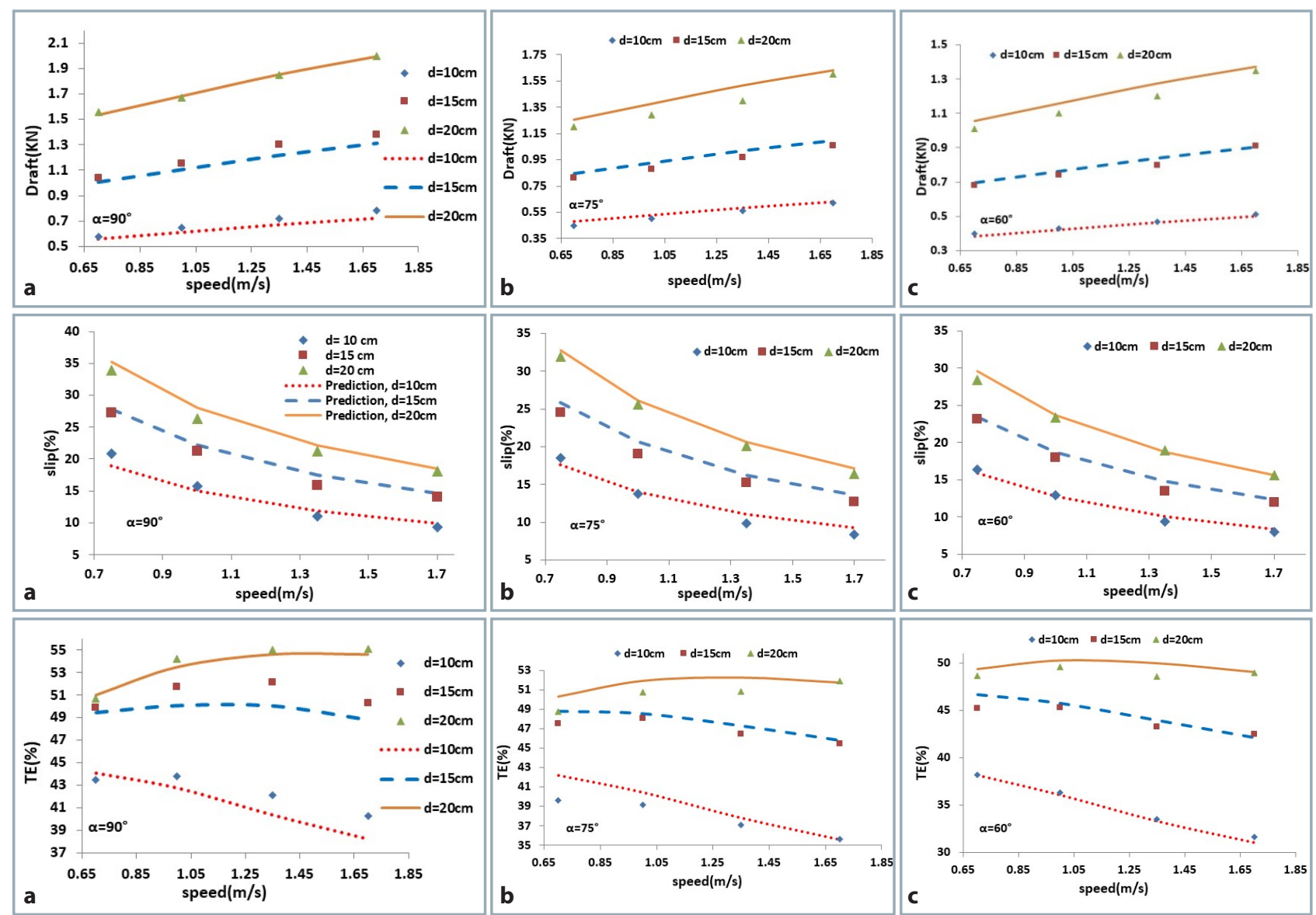

Fig. 3 Impacts of travel velocity and tillage depth on draft, slip and tractive efficiency, a) at rake angle of a) $90^{\circ}$, b) $75^{\circ}$, and c) $60^{\circ}$; lines represent estimation obtained using Eq. (7)
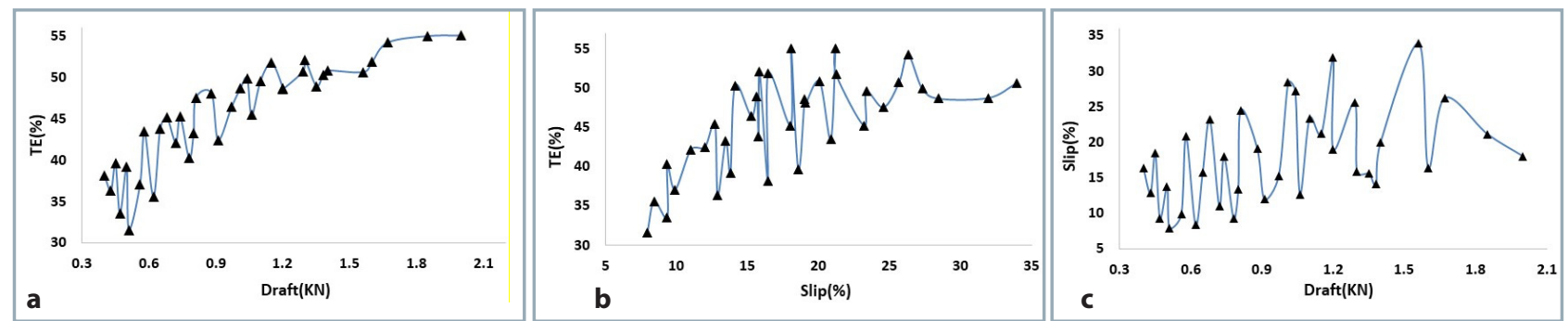

Fig. 4 a) Influence of draft on tractive efficiency, b) Influence of slip on tractive efficiency, c) Influence of draft on slip 
Table 5 Variation of tractive efficiency caused by travel velocity, tillage depth and rake angle

\begin{tabular}{|l||c|c|c|}
\hline Level & $\begin{array}{c}\text { Slip changes due to depth } \\
\text { change (\%) }\end{array}$ & $\begin{array}{c}\text { Slip changes due to velocity } \\
\text { change (\%) }\end{array}$ & $\begin{array}{c}\text { Slip changes due to rake } \\
\text { angle change (\%) }\end{array}$ \\
\hline $\mathbf{1}$ & 23.19 & 1.6 & 5.7 \\
\hline $\mathbf{2}$ & 33.2 & 0.75 & 15.04 \\
\hline $\mathbf{3}$ & - & 2.5 & - \\
\hline
\end{tabular}

from various tractions necessary for different soil types, implying the fact that in order to achieve high tractive efficiency, high traction force is needed and slip will be increased. Ranjbarian et al. (2017) reported that tractor slip was increased with increase in travel velocity and draft force. This result might have been caused by required draft force which was much higher than in this research. Their required draft exceeded standard draft range of the tractor, hence the tractor slip increasing significantly.

\section{Conclusion}

The summary of results obtained in this study is shown in Table 5, illustrating the variation of the drive wheel slip due to changes in travel velocity, rake angle and tilling depth. It shows great effect of tilling depth on tractive efficiency in comparison with the rake angle and travel velocity. The most significant impacts on the tractive efficiency had tilling depth and then rake angle. Travel velocity had merely minor impact on tractive efficiency in comparison with the two other parameters.

\section{References}

ABBASPOUR-GILANDEH, Y. - KHANRAMAKI, M. 2013. Design, construction and calibration of a triaxial dynamometer for measuring forces and moments applied on tillage implements in field conditions. In Journal of Metrology Society of India, vol. 28, no. 2, pp. 119-127.

AL-JANOBI, A. A. - AL-SUHAIBANI, S. A. 1998. Draft of primary tillage implements in sandy loam soil. In Transaction of the ASAE, vol. 14, no. 4, pp. 343-348.

ARVIDSON, J. - KELLER, T. - GUSTAFSON, K. 2004. Specific draught for mouldboard plough, chisel plough and disc harrow at different water contents. In Soil and Tillage Research, vol. 79, pp. 221-231.

BARGER, E. L. - LILJEDAHL, J. B. - CARLETON, W. M. - MCKIBBEN, E. G. 1963. Tractors and Their Power Units. New York: John Wiley. BRIXIUS, W. 1987. Traction prediction equations for bias-ply tires. ASAE Paper no. 871622. St. Joseph, Mich. ASAE.

GRISSO, R. D. - YASIN, M. - KOCHERM, M. F. 1994. Tillage implement forces operating in silty clay loam. ASAE paper no. 94-1532. St. Joseph, Mich., ASAE.
GRISSO, R. D. - PERUMRAL, J. V. - ZOZ, F. M. 2006. An empirical model for tractive performance of rubber-tracks in agricultural soils. In Journal of Terramechanics, vol. 43, no. 2, pp. 225-236.

GRISSO, R. D. - PERUMPRAL, J. V. - ZOZ, F. M. 2007. Spreedsheet for matching tractors and drawn implements. In Transaction of the ASAE, vol. 23, no. 3, pp. 259-265.

KEPNER, R. A. - BANER, R. - BARGER, E. L. 1978. Principle of Farm Machinery. AVI Publication Company.

KUMAR, L. S. - AGGARWAL, S. 2001. Effect of inflation pressure and ballasting on the tractive performance of tractor. In Journal of AMA, vol. 32, no. 3, pp. 23-26.

MAMMAN, E. - ONI, K. C. 2005. Draught performance of a range of model chisel furrowers. In Agricultural Engineering International: CIGR Journal, vol. 7, pp.1-17.

MURPHY, G. C. 1950. Similitude in Engineering. New York: Ronald Press Company.

OLATUNJI, O. M. - BURUBAI, W. I. - DAVIES, R. M. 2009. Effect of weight and draught on the performance of disc plough on sandy loam soil. In Journal of Applied Science Engineering Technology, vol. 1, no. 1, pp. 22-26.

OSINENKO, P. V. - GEISSLER, M. - HERLITZIUS, T. 2015. A method of optimal traction control for farm tractors with feedback of drive torque. In Biosystems Engineering, vol. 129, pp. 20-33.

OSKIN, S. V. - TARASENKO, B. F. 2017. Using service simulating test in designing of tillage combine. In Acta Technologica Agriculurae, vol. 20, no. 4, pp. 110-114.

RANJBARIAN, S. - ASKARI, M. - JANATKHAH, J. 2017. Performance of tractor and tillage implements in clay soil. In Journal of the Saudi Society of Agricultural Sciences, vol. 16, no. 2, pp.154-162.

RNAM. 1983. Test Code and Procedure for Agricultural Machinery. Economic and Social Commission for Asia and the Pacific. Technical Series, No. 12.

SHEBI, J. - ONI, K. C. - BRAIDE, F. G. 1988. Comparative tractive performance of three tractors. In Agricultural Mechanization in Asia, Africa and Latin America, vol. 19, no. 2, pp. 25-29.

SÖEHNE, W. 1956. Some basic considerations of soil mechanics as applied to agricultural engineering. In Grundlagen der landerchnik, vol. 7, pp. 11-27. (NIAE Translation No. 53).

ZOZ, F. M. - GRISSO, R. D. 2003. Traction and tractor performance. In ASAE distinguished lecture Series No. 27. ASAE, St. Joseph, MI, 49085-9659, USA. 